\title{
REUSE OF INORGANIC SLUDGE AS A COAGULANT ON COLLOIDAL SUSPENSION REMOVAL IN RAW SURFACE WATER TREATMENT
}

\author{
Kafeel Ahmad \\ Dept of Civil Engineering, Jamia Millia Islamia (A Central University), New Delhi-110025, India, afeeljmi@yahoo.com
}

\begin{abstract}
The potable water obtained from surface water sources usually entails the use of a coagulation-flocculation stage to remove turbidity in the form of colloidal suspensions. The coagulation performance of acidified sludge has been studied by jar test. The jar tests have been conducted using water sample collected from river Yamuna at Wazirabad, New Delhi. The acidified sludge coagulation attained comparatively high turbidity removal efficiency, and the treated water having less than 5NTU turbidity could be obtained with initial turbidities from 25 to $70 \mathrm{NTU}$. The results of turbidity removal from acidified sludge showed significant reduction (50 to $98 \%$ at variable conditions) when compared with $\mathrm{Al}_{2}\left(\mathrm{SO}_{4}\right)_{3}$. The acidified sludge as a coagulant aid has been found to be more effective than that of alum and it significantly reduces the sludge production.
\end{abstract}

Key words: recycled sludge, colloidal suspension, coagulation, surface water, turbidity removal, water treatment

\section{INTRODUCTION}

The colloidal suspensions in surface water are considered as one of the significant impurity. It is composed of inorganic and organic substances and contains at least one dimension lying within the range of ten angstrom to one micron. The colloidal suspensions can easily be removed through settling operation; however colloidal suspensions need longer detention time for the settlement. Therefore, it is essential to agglomerate two or more colloids to form flocs resulting into increase of mass density, which settles quickly. The coagulation with conventional coagulants can easily remove colloidal suspensions but the major drawback of the process is the production of voluminous sludge, which poses difficulty in handling and disposal to environmental engineers. Therefore, the substitute of conventional coagulants, which produces lesser amount of sludge and treats the water more effectively, was the major area of research for environmental scientists and researchers in the recent past. Host of researchers (Zhang et. Al., 2006; Gao et. al., 2002; Gao et. al., 2003; Edzwald and Tobiason, 2000) have reported the effectiveness of various coagulants under variable conditions on the removal of colloidal suspensions. Gao et. al. (2002) have introduced a new inorganic coagulant, aluminum-silicate polymer composite (PASiC), that was produced by two approaches: (1) hydroxylation of the mixture of $\mathrm{AlCl}_{3}$ and fresh polysilicate (PASiCc); (2) hydroxylated poly aluminum-chloride (PAC) combined with fresh polysilicate (PASiCm). The study suggest that, compared with PAC, PASiC may enhance aggregating efficiency and give better coagulating effects, but weaken charge effectiveness in coagulation process or become unstable when stored for longer time, especially at higher $B$ value and lower $\mathrm{Al} / \mathrm{Si}$ ratio. The coagulating effect of PASiC is closely linked to the preparation procedure. With the increase of $B$ value and the decrease of $\mathrm{Al} / \mathrm{Si}$ ratio, the coagulation efficiency of PASiC increases and at the same $B$ value and $\mathrm{Al} / \mathrm{Si}$ ratio, $\mathrm{PASiCc}$ seems to give a little better coagulation effect than PASiCm but less stability (Gao et. al., 2003). Edzwald and Tobiason (2000) have discussed the dual coagulation strategy of alum and cationic polymer that reduces sludge production and overall operating costs compared to alum alone. The relevant literature review shows the scarcity of coagulant that may produce lesser volume of sludge and treat the water in economical fashion. Therefore, in the present study, an attempt has been made to utilize the sludge after acidification for the removal of colloidal suspensions from contaminated surface water.

\section{MATERIALS AND METHODS}

The conventional jar test apparatus has been used for the determination of optimal coagulant dose. Initially, variable doses of alum (aluminum sulphate) ranging from 5 to $35 \mathrm{mg} / \mathrm{l}$ with an increment of $5 \mathrm{mg} / \mathrm{l}$ have been added in $2000 \mathrm{ml}$ capacity acidified sludge containing $1000 \mathrm{ml}$ water sample. Thereafter, 2 minutes flash mixing and 30 minutes slow mixing has been carried out. Then, the acidified sludge containing water are kept undisturbed for another 20 minutes to settle down flocs. Finally, turbidity of the supernatant has been measured using digital Nephlo Turbidity Meter to ascertain the removal of colloidal suspensions from water.

The sludge produced in the first stage of the coagulation through alum (aluminum sulphate) is then separated by separatory funnel. The sludge obtained is acidified with various amount of sulphuric acid of variable normalities ranging from $0.5 \mathrm{~N}$ to $3 \mathrm{~N}$ with an increment of $0.5 \mathrm{~N}$. The 
quantity of acid to mix with sludge has been experimentally determined (Table 1, Figure 1).

Table 1: Summary of turbidity reduction at variable dosage of acidified sludge

\begin{tabular}{|c|c|c|c|c|c|c|}
\hline \multirow{2}{*}{$\begin{array}{c}\text { Percentage } \\
\text { of acid } \\
\text { concentration }\end{array}$} & \multicolumn{6}{|c|}{ Acidified sludge dosage, $\mathrm{ml} / 1$} \\
\cline { 2 - 7 } & 2 & 4 & 6 & 8 & 10 & 12 \\
\hline 0.02 & 55.4 & 57 & 60.4 & 69.6 & 72.5 & 74.1 \\
\hline 0.04 & 74.6 & 86.6 & 88.7 & 93.3 & 93.8 & 92 \\
\hline 0.06 & 86.3 & 89.6 & 92.5 & 94.2 & 94.2 & 93.8 \\
\hline 0.08 & 88.3 & 90.4 & 92 & 94.6 & 94.2 & 96.7 \\
\hline 0.10 & 89.6 & 93.8 & 93.8 & 95.4 & 97.5 & 97.5 \\
\hline 0.12 & 91.3 & 92.5 & 97.1 & 98.3 & 99.2 & 99.2 \\
\hline
\end{tabular}

The trends of figure show that the increase of percent acid increases the percentage reduction of turbidity at all dosage. Initially, variation in turbidity reduction seems to be very sharp and then decreases slightly. The optimum quantity of acid used for the acidification of sludge lies between 0.04 to $0.06 \%$. After $0.06 \%$ of acid, the percentage turbidity reduction increases but the increase is slight and the use of further acid seems to be uneconomical. Therefore, in the present study, the sludge is acidified with typical quantity of acid $0.05 \%$ i.e. 0.05 $\mathrm{ml}$ acid/1 ml sludge.

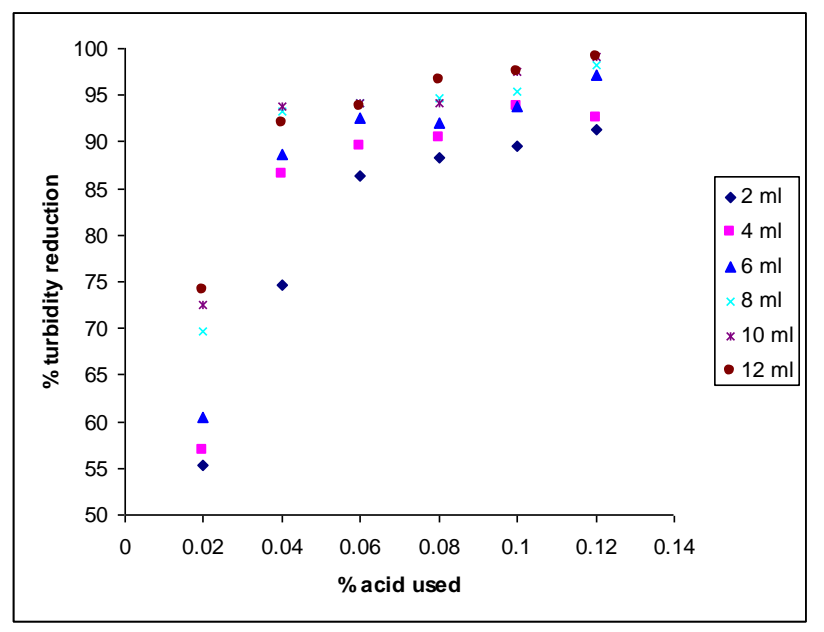

Fig. 1: Quantity of acid used for acidification of sludge and its removal efficiency

The acidified sludge of variable normalities ranging from $0.5 \mathrm{~N}$ to $3.0 \mathrm{~N}$ with the increment of $0.5 \mathrm{~N}$ are then, used as a coagulant for the removal of colloidal suspensions from contaminated surface water at normal $\mathrm{pH}$ conditions. The $\mathrm{pH}$ and turbidity has been measured before and after the treatment of surface water. The percentage turbidity removal can be evaluated by the expression

Percentage turbidity removed $=\frac{\text { Initial turbidity }- \text { Turbidity remains }}{\text { Initial turbidity }} \times 100$

\section{RESULTS AND DISCUSSION}

Fig.2 shows that the maximum removal of turbidity, $12.5 \%$ is observed at $12 \mathrm{ml} / 1$ dose of $0.5 \mathrm{~N}$ acidified sludge; whereas the minimum (3.0\%) at $2 \mathrm{ml} / \mathrm{l}$ of acidified sludge dose of $0.5 \mathrm{~N}$ (Table 2). The trend of percentage reduction shows that turbidity removal increases with increase of dose of acidified sludge. The significant turbidity reduction starts with $1.5 \mathrm{~N}$ normal acidified sludge. The maximum reduction is observed at $12 \mathrm{ml} / \mathrm{l}$ dose of $1.5 \mathrm{~N}$ acidified sludge whereas $39.6 \%$ minimum at $2 \mathrm{ml} / \mathrm{l}$ dose of acidified sludge. Furthermore, the Figure 2 and 3 and Table 2 and 3 shows that acidified sludge dose directly affect the turbidity reduction efficiency. At higher dosage the percentage reduction is maximum and viceversa.

Table 2: Effect of variable dosage of acidified sludge on turbidity reduction

\begin{tabular}{|c|c|c|c|c|c|c|}
\hline \multirow{3}{*}{$\begin{array}{l}\text { Acidified } \\
\text { sludge } \\
\text { Dose, } \\
\mathrm{ml} / \mathrm{l}\end{array}$} & \multicolumn{6}{|c|}{ Normality of acidified sludge } \\
\hline & $0.5 \mathrm{~N}$ & $1.0 \mathrm{~N}$ & $1.5 \mathrm{~N}$ & $2.0 \mathrm{~N}$ & $2.5 \mathrm{~N}$ & $3.0 \mathrm{~N}$ \\
\hline & \multicolumn{6}{|c|}{ Percentage turbidity reduction } \\
\hline 2 & 3 & 6.15 & 39.6 & 69.6 & 83.4 & 88.8 \\
\hline 4 & 6.15 & 6.15 & 41.15 & 75.4 & 87.5 & 90.4 \\
\hline 6 & 7.7 & 6.9 & 44.6 & 89.6 & 92.3 & 98.5 \\
\hline 8 & 8.8 & 8.5 & 44.6 & 95 & 94.2 & 98.8 \\
\hline 10 & 9.6 & 11.5 & 54.6 & 97.5 & 96.5 & 98.8 \\
\hline 12 & 12.5 & 11.5 & 57.7 & 98.5 & 98.5 & 98.8 \\
\hline
\end{tabular}




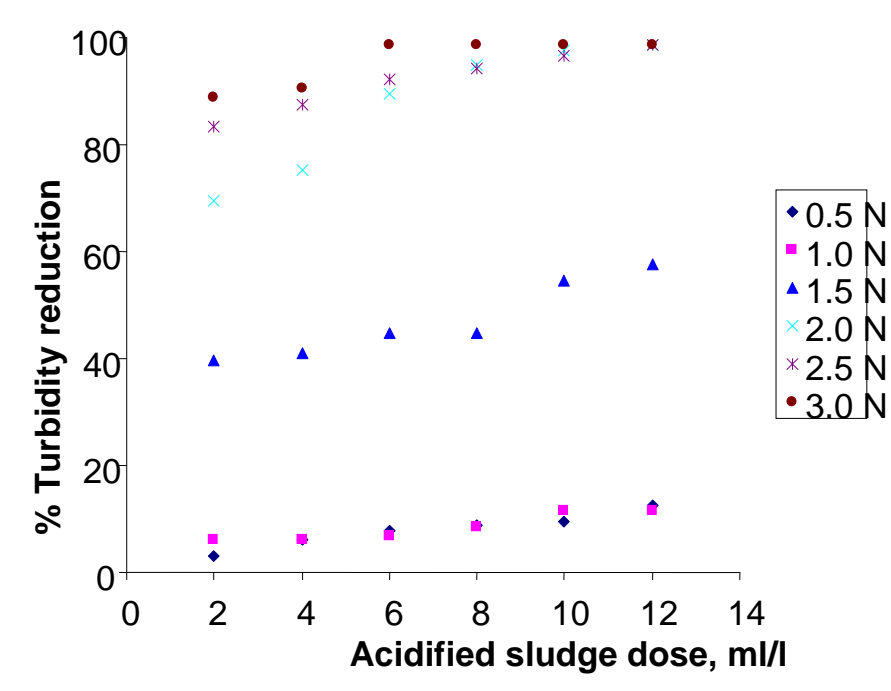

Fig. 2: Trends of turbidity reduction at various acidified sludge dosage

The normality of acidified sludge is another major factor that affects the percentage turbidity reduction. As the normality of acidified sludge increases, the percentage reduction increases and attains its significant value after $1.5 \mathrm{~N}$. The optimum normality has been observed as $2.5 \mathrm{~N}$ and $3.0 \mathrm{~N}$, since the maximum reduction (95 to $98 \% 0$ is obtained at these normalities. It is also observed that the $\mathrm{pH}$ of water during experiments remain almost unchanged. It is always found to be in the range of 6.8 to 7.7 , which is within the permissible range of drinking water as prescribed by IS: 10500 (1993). The comparison of results with conventional alum shows that acidified sludge of more than two normality is more effective than alum on the removal of colloidal suspensions.

Table 3: Effect of normality on percentage turbidity reduction

\begin{tabular}{|c|c|c|c|c|c|c|}
\hline \multirow{2}{*}{$\begin{array}{l}\text { Normality of } \\
\text { acidified } \\
\text { sludge, N }\end{array}$} & \multicolumn{6}{|c|}{ Acidified sludge dosage, ml/l } \\
\cline { 2 - 7 } & 2 & 4 & 6 & 8 & 10 & 12 \\
\cline { 2 - 7 } 0.5 & 3 & 6.15 & 7.7 & 8.8 & 9.6 & 12.5 \\
\hline 1.0 & 6.15 & 6.15 & 6.9 & 8.5 & 11.5 & 11.5 \\
\hline 1.5 & 39.6 & 41.15 & 44.6 & 44.6 & 54.6 & 57.7 \\
\hline 2.0 & 69.6 & 75.4 & 89.6 & 95 & 97.5 & 98.5 \\
\hline 2.5 & 83.4 & 87.5 & 92.3 & 94.2 & 96.5 & 98.5 \\
\hline 3.0 & 88.8 & 90.4 & 98.5 & 98.8 & 98.8 & 98.8 \\
\hline
\end{tabular}

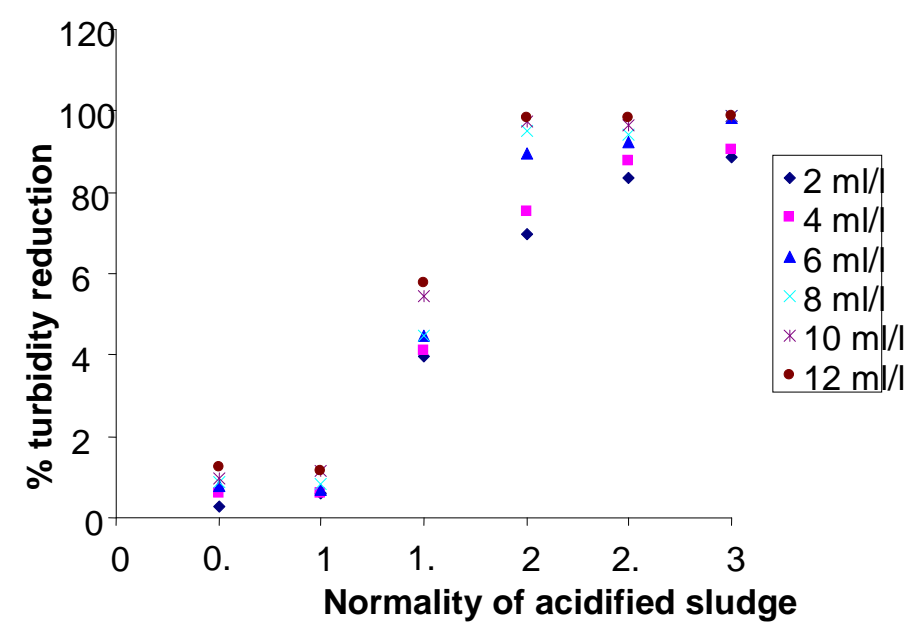

Figure 3: Trends of turbidity reduction at various normalities of acidified sludge

\section{CONCLUSIONS}

The small scale batch system experimentation shows the colloidal suspensions removal efficiency of acidified sludge. The trends of colloidal suspension removal (which has been measured in terms of turbidity) are observed almost similar for all normalities of variable acidified sludge doses. The percentage removal increases with increase in normality of acidified sludge for a particular dose and the dose of acidified sludge directly affect the reduction of turbidity. The comparison of results of alum with acidified sludge shows that acidified sludge is more effective than that of alum. The results clearly indicate that acidified sludge is an effective coagulant, which can be used in the removal of colloidal suspensions from contaminated surface water. The major advantage of acidified sludge is less production of sludge than that of alum and the produced sludge can be efficiently reused for further removal of colloidal suspensions. Although the study is carried out at laboratory scale, but on the basis of observations it can be implemented on larger scale.

\section{REFERENCES}

[1] Benefield, L.D., Judkins, J.F. and Weand, B.L. (1982) Process chemistry for water and waste water treatment, Printice Hall, Inc., Englewood Cliffs, New Jersey 07632.

[2] Byun, S.O.H, Lee, B.Y. and Lee, S (2005) improvement of coagulation efficiency using instantaneous flash mixer ( IFM ) for water treatment colloids and surface: A physicochemical and engineering aspects ( in press )

[3] Edzwald,J.K. and Tobiason, J. E. (2000) Enhanced coagulation : US requirement and a broader view, Water Science and Technology, Volume 40, Issue 9, Pages $63-70$ Gao, B.Y., Hahn, H.H. and Hoffmann, E. (2002) Evaluation of aluminum - silicate polymer composite as a coagulant for 
water treatment, Water Research Volume 36, Issue 14, Pages $3573-3581$

[4] Gao, B Y., Yue,Q Y., Wang B. J. and Chu, Y. B. (2003) poly - aluminum - silicate chloride ( PASiC ) - a new type of composite inorganic polymer coagulant colloids and surface A: Physicochemical and Engineering Aspect Volume 229, Issue 1-3, Pages 121-127

[5] Jiang, J.Q. and Lloyd, B. (2002 ) Progress in the development and use of ferrate ( VI ) salt as an oxidant and coagulation for water and waste water treatment, Water Research Volume 36 Issue 6, Pages 1397-1408

[6] Kuusik, R. and Viisimaa, L. (1999) A new coagulant for water purification, Water Research, Volume 33, Issue 9, Pages $2075-2082$.

[7] Packham, R.F. (1962) The theory of the coagulation process - a survey of the literature part I \& II Proc. Soc. Water treatment \& examination Pages 50 -106.

[8] Standard methods for the examination of water and waste water (1998), $20^{\text {th }}$ edition, Jointly Published by American Public Health Association \& American Water Association and Water Environment Federation.

[9] Thompson, C.G , Sinley, T.E., Black, A.P. ( 1972 ) magnesium carbonate - a recycled coagulant, part I \& II, Journal of American Water Works Association.

[10] Verma, S. ( 1975 ) Colloid chemical parameters for coagulant dose control, M. Tech dissertation, IIT Kanpur, Kanpur, U P, India

[11] Wickramasinhe, S.R., Han, B., Zimbron, J., Shen and Karim, M.N. (2004) Acidified sludgeenic removal by coagulation and filtration : comparison of ground waters from the United States and Bangladesh, Desalination, Volume 169, Issue 3, Pages 231- 244 